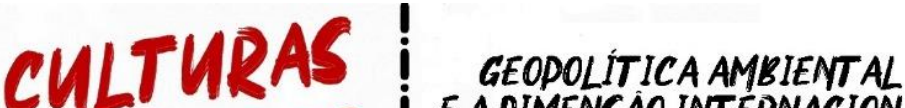 JUREDICAS
}

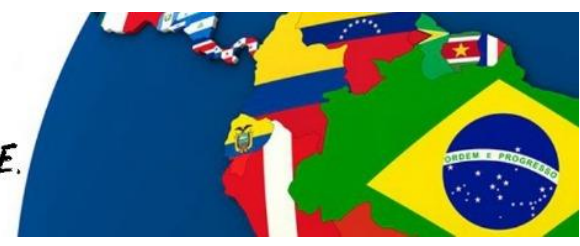

\section{GEOPOLÍTICA AMBIENTAL E A DIMENSÃO INTERNACIONAL DA PROTEÇÃO DO MEIO AMBIENTE ${ }^{1}$}

\section{ENVIRONMENTAL GEOPOLITICS AND THE INTERNATIONAL DIMENSION OF ENVIRONMENTAL PROTECTION}

\author{
Giovani Orso Borile ${ }^{2}$ \\ Cleide Calgaro ${ }^{3}$
}

\begin{abstract}
Resumo: O presente estudo desenvolve uma análise acerca da Geopolítica e da aplicação dos seus conceitos e práticas na seara do meio ambiente e na proposta de proteção ambiental. Objetiva-se demonstrar sua efetividade no que tange às questões ambientais tanto locais como de cunho transnacional, trazendo-se a proposta da Geopolítica Ambiental como o estudo das questões territoriais, políticas e ecológicas com ênfase maior na dinâmica internacional. Apresenta-se através de um processo analítico e interpretativo as principais nuances e perspectivas da geopolítica ambiental e sua importância para a conservação e proteção dos recursos naturais. Outrossim, por meio da compreensão da relação entre poder e território sob a perspectiva geopolítica buscou-se evidenciar como ela pode auxiliar com a causa ambiental, sendo posteriormente observada a resposta ao problema de pesquisa no desenvolvimento da geopolítica e sua potencialidade em viabilizar uma visão integrada do meio ambiente ao desenvolver mecanismos de gestão internacional dos ecossistemas a partir do caráter de transnacionalidade dos recursos naturais.
\end{abstract}

Palavras-chave: Novos Direitos; Geopolítica Ambiental; Território; Direito Internacional Ambiental; Políticas Ambientais Internacionais.

Abstract: The present study develops an analysis about Geopolitics and the application of its concepts and practices in the environmental field and in the proposal of environmental protection. It aims to demonstrate its effectiveness in relation to local and transnational environmental issues, bringing the proposal of Environmental Geopolitics as the study of territorial, political and ecological issues with a greater emphasis on international dynamics.

\footnotetext{
${ }^{1}$ Artigo recebido em 25/04/2018 e aprovado em 12/07/19

${ }^{2}$ Doutorando e Mestre em Direito Ambiental pela Universidade de Caxias do Sul - UCS. Graduado em Direito pela Universidade de Caxias do Sul - UCS. Graduando em Sociologia pela Universidade Paulista - UNIP. Integrante do Grupo de Pesquisa "Metamorfose Jurídica". CV: http://lattes.cnpq.br/9063196599611399. E-mail: goborile@ ucs.br. ORCID: orcid.org/0000-0003-4545-1385

3 Doutora em Ciências Sociais na Universidade do Vale do Rio dos Sinos - UNISINOS. Pós-Doutora em Filosofia e em Direito ambos pela Pontifícia Universidade Católica do Rio Grande do Sul - PUCRS. Doutoranda em Filosofia pela PUCRS, na condição de taxista CAPES. Professora da Graduação e Pós-Graduação em Direito na Universidade de Caxias do Sul. É vice-líder do Grupo de Pesquisa "Metamorfose Jurídica" da Universidade de Caxias do Sul-UCS e do Grupo de Pesquisa "Filosofia do Direito e Pensamento Político" da Universidade Federal da Paraíba-UFPB. Atua como pesquisadora no Grupo de pesquisa "Regulação ambiental da atividade econômica sustentável (REGA)" da Escola Superior Dom Helder Câmara. Orcid: https://orcid.org/0000-00021840-9598. CV: http://lattes.cnpq.br/8547639191475261. E-mail: ccalgaro1@ hotmail.com. ORCID: orcid.org/0000-0002-1840-9598.
} 
The main nuances and perspectives of environmental geopolitics and their importance for the conservation and protection of natural resources are presented through an analytical and interpretative process. Also, through the understanding of the relationship between power and territory from the geopolitical perspective, it was tried to show how it can help with the environmental cause, being later observed the answer to the research problem in the development of geopolitics and its potential to make possible an integrated vision of the environment by developing mechanisms for the international management of ecosystems based on the transnational character of natural resources.

Keywords: New Rights; Environmental Geopolitics; Territory; International Environmental Law; International Environmental Policies.

\section{Considerações iniciais}

O estudo das relações internacionais é fundamental para o desenvolvimento de políticas ambientais de cunho protetivo. A análise de um método de atuação integrada no contexto ambiental pode contribuir significativamente para a proteção dos ecossistemas, de modo que, propõe-se o desenvolvimento de uma geopolítica ambiental para uma governança global fundada nos princípios de um desenvolvimento equilibrado.

Por conseguinte, o presente trabalho tem como objetivo, através de um exercício analítico e interpretativo, ponderar o desenvolvimento da geopolítica e enfocar a perspectiva ambiental a partir da condição de transnacionalidade presente no tema, discutindo desse modo a atualidade da geopolítica no contex to ambiental.

O principal questionamento se traduz em como a compreensão da relação entre poder e território, sob uma perspectiva geopolítica, pode contribuir para a causa ambiental de modo a permitir uma interpretação da dimensão transnacional do meio ambiente, desde sua configuração como direito humano à sua tutela internacional.

A partir do estabelecimento de um parâmetro geopolítico de compreensão da complexidade da questão ambiental influi-se acerca da necessidade de implantação de um pensamento transnacional da temática ecológica, incutindo uma perspectiva global de consideração ecossistêmica e proporcionando um estudo integrado da problemática.

$\mathrm{Na}$ primeira seção faz-se um exame acerca dos conceitos introdutórios da Geopolítica, avaliando-se sua fundamentação e dimensões tanto no que diz respeito à Geopolítica clássica como na contemporânea, posteriormente na segunda seção é apresentada a Geopolítica Ambiental e sua utilização como instrumento de proteção ao meio ambiente e recursos naturais e por fim traz-se a dimensão transnacional da conservação ecológica, 
averiguando-se a temática geopolítica aplicada à materialização da proteção dos ecossistemas transnacionais pelas políticas internacionais.

\section{Aspectos preliminares da geopolítica: território, poder e Estado}

Primeiramente, há de se mencionar que a geopolítica é a área do conhecimento que analisa a importância do território e espaço geográfico e sua influência no desenvolvimento do Estado, é considerada "um campo de conhecimento transdisciplinar" (OLIVEIRA, 2012, p. 78) que estuda o plano de estratégias a serem utilizadas pelos países e seus governos como forma de materializar os interesses da nação, apresentando "um objeto de estudo definido e que se confunde com as bases geográficas do poder do Estado" (ALBUQUERQUE, 2011, p. 26).

A instituição da geopolítica é de suma importância para o estabelecimento da diplomacia e reciprocidade entre países, permitindo a realização de políticas de cooperação mútua como forma de garantia da manutenção do bem-estar social, desenvolvendo-se políticas externas como forma de planejamento estratégico territorial de cunho diplomático ou protetivo. (LACOSTE, 2008, p. 19). A influência do espaço geográfico na política é bem observado como menciona Waldeir Eustáquio dos Santos (2011, p. 80):

\footnotetext{
A geopolítica utiliza-se dos conhecimentos geográficos e políticos, o objetivo primeiro é acadêmico, mas pode e é constantemente utilizada para aumentar a força dos Estados. É interessante o uso da disciplina como estratégia e possibilita observar como o espaço influência na política e a maneira como a geografia interfere na política. Uma das causas do conflito é a falta de espaço no mundo e os grandes Estados sempre buscam maior quantidade de terras, seja para população, ou para investimentos econômicos. Essa foi uma das estratégias do mercantilismo, o princípio que culminou na política colonial. A ligação de um povo com o solo pode determinar o poder de um país.
}

Dessa forma, ao mencionar-se a questão da Geopolítica como ciência torna-se indispensável uma abordagem da noção de domínio territorial, sendo constituído como o espaço concreto em marcos e pontos limítrofes estabelecidos, definido como demarcação do espaço geográfico e paisagem de domínio estatal, onde as relações territoriais acabam projetando as "relações da geopolítica com os desígnios expansionistas das potências mundiais" (GANDRA, 2013, p. 28), outrossim, as dimensões geográficas e territoriais é que influenciam o contexto geopolítico, norteando a adoção de medidas administrativas como meio de gestão do espaço, garantindo a plena ocupação, restrição e proteção das áreas estatais 
por meio de uma gerência voltada à manutenção do espaço social e consequentemente do meio ambiente. (SUNDBERG, 2017, p. 27)

A geopolítica assim sendo procura interpretar as relações recíprocas entre o poder político governamental e o espaço geográfico, buscando um ponto de equilíbrio entre as ações internacionais singulares orientando a atuação dos Estados no plano global e viabilizando uma conexão mais precisa das relações internacionais sem, contudo, impossibilitar a atuação conjunta e a firme cooperação em face aos interesses tanto externos quanto internos, o que é de grande relevância quando se mencionam questões referentes à recursos naturais e meio ambiente que obrigatoriamente abarcam a noção de transnacionalidade, sendo de suma importância o estudo das "estratégias geopolíticas das grandes potências no mundo" (BROZOSKI, 2013, p. 58).

Dessa forma, enfatiza-se a adoção de um pensamento diplomático e a utilização do poder político em face de seu território através de uma concepção transnacional, o que sem dúvidas abriga a temática do Direito Ambiental Internacional como conteúdo obrigatório principalmente no que tange à Geopolítica Ambiental, visto que nele "está em pauta a constituição de uma nova maneira de se fazer geopolítica, onde através de uma atmosfera pacífica encontros diplomáticos selam formas contemporâneas de domínio do território". (OLIVEIRA, 2011a, p. 07)

Destarte, através do exercício da integração e da adoção de parâmetros diplomáticos de cooperação, se estabelece uma ação governamental em prol das garantias do povo e de seus interesses em face ao plano internacional, garantindo-se, como forma de resposta aos mais complexos impasses, a implantação de mecanismos internacionais de resolução de conflitos, desenvolvendo-se as relações de poder associadas ao raciocínio geográfico e territorial através das políticas internacionais, como precisamente leciona Gaspard Rwanyiziri (2009, p. 17).

Sob esta conjuntura é possível afirmar que o contributo geopolítico pretende estabelecer postulados específicos de resolução de conflitos, que aplicados "na análise de situações concretas interessando ao jogo de forças estatais projetados no espaço (COSTA, 2008, p. 55) permite a compreensão do fenômeno espacial ou geográfico a partir da problemática em que está inserido, possibilitando "a proposição de diretrizes políticas formuladas à luz dos fatores geográficos" como bem menciona Golbery do Couto e Silva (1967, p. 64).

Sem dúvidas, o ponto nuclear é firmado pela necessidade de adoção de Políticas Internacionais e a questão toca, indiscutivelmente, a seara ambiental, o que por si só já denota 
pertinência, destacando-se que o referido ponto constitui-se num dos maiores dilemas da Geopolítica, a administração das questões ambientais no plano transnacional, o que requer uma série de medidas e estratégias como meio de solução da problemática concernente aos recursos naturais e biodiversidade no plano global, sendo que a questão "dos recursos naturais, ou ativos estratégicos, tem passado a ser tema central na análise geopolítica e geoestratégica comum". (CARMONA, 2012, p. 137).

Os mais pertinentes estudos de Geopolítica na atualidade tendem a realizar uma análise profunda das relações globais entre as nações e toda a problemática que permeia a questão, focando nas ações e práticas realizadas com o intuito de materializar o poder e âmbito de domínio no discurso e em acordos, configurando-se em "uma geopolítica que seria comprometida eticamente com a paz, a democracia e a justiça social” (COSTA, 2008, p. 249) o que inegavelmente envolve gerenciamento, administração e o controle dos territórios nacionais, como ocorreu nas discussões referentes ao Mar Cáspio e a questão do petróleo. (ZEINOLABEDIN; YAHYAPOUR; SHIRZAD, 2009, p. 120).

Consequentemente, ao se analisar as estratégias e relações transnacionais envolvendo os Estados, busca-se o desenvolvimento e ampliação das medidas administrativas tanto internas quanto externas que venham a envolver a materialização dos interesses por meio das leis, políticas públicas, espaço geográficos e recursos naturais, pautando-se ainda nas relações diplomáticas existentes e suas medidas relacionadas aos demais estados, de modo que, a "geopolítica não pode ser considerada somente um objeto de estudos mas principalmente método de conhecimento, sendo este aplicado em todas as nações do mundo atual" (GOMES, 2013, p. 21).

Diante do exposto, se preconiza uma postura inquisitiva, analítica e crítica como forma de averiguar o panorama histórico e atual das múltiplas visões das relações políticas globais, unindo elementos de estudo do espaço físico e seus recursos sociais, econômicos e ambientais com elementos de política, organização e domínio do Estado, firmando-se na interação entre a política de poder dos Estados e suas relações com o mundo globalizado, dado que "a geopolítica crítica como metodologia implica uma análise dos fenômenos e fatos da geopolítica" (FONT; RUFÍ, 2006, p. 48) a partir de uma visão global.

Com isso considera-se sempre a máxima de que o Estado busca promover sua função de defender o território nacional como foco de seu poderio em face ao cenário internacional, disciplinando seus territórios, embasado nos acordos internacionais e diplomáticos e buscando a resolução dos conflitos ou disputas referentes ao espaço geográfico e recursos por ele abrigado, procurando sempre o aproveitamento pleno do espaço territorial e a imposição de 
limites pelo poder estatal como metodologia de proteção do território, garantindo a sua segurança e a possibilidade de lucro através da exploração econômica, figurando o Estado como centro das decisões estratégicas. (ESPAÑA, 2016, p. 11).

\section{A Geopolítica Ambiental e sua aplicação como instrumento de proteção ao meio ambiente}

A questão ambiental gera inúmeras discussões no que toca à geopolítica, de modo que a referida ao examinar as práticas administrativas governamentais torna-se figura essencial para o estudo das práticas estatais que colocam em risco o dito espaço vital de cada Estado. Logicamente, para a manutenção do espaço vital é imprescindível a conservação do ambiente natural e processos ecológicos que o integram, assim, haverá uma efetiva atividade protetiva que vislumbre a continuidade do Estado conjuntamente com seu povo e território, uma vez que "no contexto geopolítico [...] são crescentes os interesses ligados à valorização do capital natural" (BECKER, 2005, p. 77).

Há de se mencionar que ao abordarem-se as estratégias e metodologias de gerenciamento estatal sempre se busca um método de interação e relacionamento político diplomático quando de questões referentes a dois ou mais países envolvidos em qualquer dilema, portanto, tratando-se de matéria ambiental, inevitavelmente, serão abordados temas transnacionais e de cunho eminente para a subsistência do gênero humano e consequentemente do poder estatal. Desse modo há "una preocupación geopolítica que pone en relieve el acceso a los recursos [...] y la estructuración de los territorios" (NAVA; GANDIN, 2015, p. 122), sendo que, a plena e efetiva administração da matéria de cunho ambiental é imprescindível para a sobrevivência humana e de grande valia para as relações internacionais, como salienta Albagli (1998, p. 23) "a atual problemática da biodiversidade é uma questão ao mesmo tempo 'tecno(eco)lógica' e geopolítica, caracterizando seus principais desdobramentos e conflitos no plano internacional". Nesse sentido, Martins e Pianovski (2013, p. 34), pontuam em profunda análise que:

A questão ambiental encontra sua dimensão geopolítica em [...] respeito à escassez de recursos cruciais para a sobrevivência humana. Quando tais recursos começarem a faltar para as populações dos países desenvolvidos do norte, os vácuos de poder localizados na América Latina, África e Ásia são (e serão) alvos da ocupação econômica ou mesmo de intervenções militares. Esta é uma situação potencial que não deve ser ignorada, em primeiro lugar por que o mundo já testemunhou experiências como estas: em 1967, Israel tomou da Síria as colinas de Golan para assumir controle de nascentes de água potável; em 1963 Brasil e França 
mobilizaram suas marinhas para guerrear pelo pescado de lagosta nas costas brasileiras; a escassez de alimentos estimulou o ódio entre Hutus e Tutsis em Ruanda, levando o massacre dos segundos pelos primeiros. Na realidade, a escassez de recursos é um dos pontos centrais da questão ambiental moderna.

Assim sendo, o desenvolvimento das mais variadas técnicas e modos de produção exploratória, impulsionadas e financiadas pelos sistemas de capital e mercado das indústrias fomentaram a escassez dos mais variados recursos ambientais e demandaram em grande afã a exploração de recursos minerais e de energia para sustentar em pleno andamento a atividade extrativista e industrial.

Outrossim, observa Leff (2005, p. 07) que "en la geopolítica del desarrollo sostenible se pone en juego una distribución ecológica derivada de la localización geográfica de los países" ou seja, os Estados em posição desfavorável tendem a suportar o ônus de sua localização em face a possíveis disputas ambientais, o contrário também é verdadeiro visto que os países privilegiados passam a prevalecer econômica, política e socialmente em relação aos geograficamente desfavorecidos, de modo que as vantagens e conveniências oriundas de seu território viabilizam a tomada de decisões de cunho geopolítico. Esses se constituem nos mais correntes problemas e objetos de estudo da Geopolítica Ambiental, de modo que a geopolítica desenvolve um papel substancial ao desenvolver o diálogo no plano global e viabilizar a adoção de medidas transnacionais como forma de promoção do sucesso na demanda, demonstrando-se, assim, a importância "ambiental da atividade geopolítica e de sua inserção em um meio social" (MURADÁS, 2008, p. 16). Ainda, Saavedra (2013, p. 06) nos alerta que:

\begin{abstract}
Otra característica de la geopolítica de la globalización es que la variable ambiental y la variable energética se transforman en un sólo fenómeno con dos caras. Esto es así porque la llamada Civilización Industrial depende de los combustibles fósiles carbón, gas y petróleo- para su funcionamiento (particularmente del petróleo, como fuente de energía primaria). Y, como es sabido, los combustibles fósiles son los grandes emisores de dióxido de carbono (C02), que a su vez es el más importante de los GEI de raíz antropogénica [...] El gran problema es que durante las próximas décadas la matriz energética seguirá dependiendo de los combustibles fósiles.
\end{abstract}

Logo, a constante depredação ambiental, social e cultural e a escassez dos recursos naturais tão estimáveis, necessários à manutenção da vida, são questões que representam o ápice de uma problemática mundial que vem se desenvolvendo na história da humanidade, sendo que todas as manifestações e proposições políticas governamentais e ambientalistas no plano internacional, que ao sintetizarem os problemas ambientais tratados na ordem global, são considerados instrumentos aptos e idôneos na visão da Geopolítica como ciência. 
Uma vez que a atuação estatal ao agir por meio de políticas públicas ambientais no intercurso global permite que seus anseios sejam materializados e concretiza a garantia de que todos os moradores do planeta gozem de um meio ambiente ecologicamente equilibrado como medida democrática de justiça social e ambiental, "a geopolítica vem apresentando várias contribuições ao estudo da relação entre recursos naturais e conflito" (PFRIMER, 2009, p. 07).

À vista disso, a materialização de uma Geopolítica Ambiental concreta tem sido chancelada pelos inúmeros tratados e acordos internacionais envolvendo a questão ambiental e seus desdobramentos no plano global, onde foram programadas inúmeras convenções, tratados, protocolos e conferências para discussão da causa ambiental e o futuro do planeta. (O’SULLIVAN; OVERLAND; SANDALOW, 2017, p. 03)

Contudo, esses movimentos acabaram encontrando o principal empecilho nas barreiras interpostas pelas nações mais desenvolvidas economicamente que não vislumbravam a possibilidade e necessidade de diminuir o seu desenvolvimento econômico e, portanto, não anuíram aos tratados e protocolos de comprometimento para minimização dos impactos ambientais ocasionados pelo atual programa de crescimento e industrialização global que tanto lesionam o meio ambiente, portanto, em face ao amadurecimento do conceito geopolítico Campello corrobora com a ideia de que "a ecologia, neste século, é um novo parâmetro da geopolítica mundial, que, por meio de mecanismos ideológicos e pressões políticas variadas, tenta impor o ambiente como um projeto nacional aos países periféricos" (2013a, p. 143).

Nesse caso, ao desenvolver-se uma nova concepção de geopolítica fundada em um ambiente comum a todos, os programas e estratégias dos Estados, contribuíram para a resolução do problema que em certos lugares ainda continua em aberto, de modo que as principais ferramentas e instrumentos da Geopolítica Ambiental, as alianças internacionais, apresentam também o seu "calcanhar de Aquiles" em face da ausência de compromisso por parte dos países relapsos e displicentes que ao ignorarem a ideia de justiça social e ambiental não atendem aos interesses conjuntos da comunidade global que prezam pela sua subsistência e continuidade, propiciada apenas pela manutenção do ambiente onde todos os indivíduos se desenvolvem. (TORRES, 2015, p. 74)

Desse modo é indispensável “a imposição geopolítica ambientalista sobre o [...] símbolo ecológico de um contexto global de ambientalização" (CAMPELLO, 2013b, p. 125), de modo a garantir a democratização do meio ambiente, bem como, de todo o complexo de questões ambientais e ecológicas. 
De fato, o meio ambiente sadio é de suma importância para a preservação do espaço geográfico vital e portanto reclama a adoção de mecanismos aptos à permitir o deslinde das mais variadas problemáticas que permeiam as relações internacionais, assim, aderindo-se à uma metodologia factual e proativa, sem dúvidas, concretizar-se-á a solução de questões outrora impassíveis de solução, pois sem o empenho internacional e aplicação de mandamentos transnacionais de coibição ao dano ambiental, que tanto violam o senso de liberdade e a existência humana, não será possível viabilizar a proteção ambiental. (DACLON, 2008, p. 237).

Assim sendo, considerando-se que a geopolítica nos leva a investigar as metodologias pelas quais o Estado desenvolve suas políticas no plano geográfico e em seu ambiente, nada mais relevante do que analisar o modo e os instrumentos utilizados para que os referidos governos perfectibilizem seus interesses no plano espacial transnacional, visando manter a sua continuidade e segurança para a sociedade tanto no âmbito interno como externo, de forma a permitir, como disserta Ramiaramtsoa, Blanc-Pamard e Pinton (2012, p. 26) uma "lecture géopolitique de la question environnementale", e, por fim, estabelecer o ideal de que a percepção de geopolítica concretizada pelas políticas estatais seja um amplo instrumento de tutela ambiental no contexto internacional, construindo, assim, um conceito efetivo e com total aplicabilidade nas inúmeros situações referentes à seara ambiental.

Como conclui Martins e Pianovski (2013, p. 39) "a noção de política de poder com a temática ambiental [...] é a prática dos Estados de projetar para o cenário internacional o seu poder nacional, e este último, possui várias facetas e se manifesta de diferentes maneiras", requisitando, outrossim, os mais variados instrumentos de atuação para solução da problemática ambiental mundial. (PALTSEV, 2016, p. 390).

\section{A Geopolítica Ambiental e a dimensão internacional: a instrumentalização da} geopolítica e a materialização da proteção dos ecossistemas transnacionais pelas práticas internacionais

Conforme mencionado na seção anterior, a Geopolítica Ambiental mostra-se de copiosa relevância para o atual cenário mundial, de modo que as análises por ela efetuadas são de suma importância para preservação do meio ambiente e muito é relatado acerca do caráter transnacional dos recursos ambientais e sua importância para a continuidade e sobrevivência do gênero humano e demais espécies existentes no planeta. Contudo, os meios pelos quais se concretiza a proteção do ambiente internacional ainda merecem estudo e um 
exame mais acurado, de modo a desenvolverem-se mais profundamente as formas de solução das questões ambientais já recorrentes devido à modernidade. (BOSSELMANN, 2015, p. 85).

Inúmeros, sem dúvidas, são os instrumentos pelos quais se perfectibiliza a Geopolítica Ambiental, porém os mais recorrentes e exequíveis no plano da efetividade são as Políticas Públicas internacionais e as Normativas Internacionais, que contribuem de modo singular para a proteção dos recursos naturais no plano global. (CAUBET, 2013, p. 17).

As Políticas Públicas no plano internacional se constituem em amplo instrumento e estratégia efetiva de atuação na seara ambiental, se traduzem em conjuntos de práticas, programas, ações e atividades promovidas e desenvolvidas pelo Poder Estatal de forma direta ou indireta, integrada com a presença e contribuição de entes públicos, bem como de entidades privadas que ao desenvolverem suas atividades visam garantir e preservar determinados direitos para fomentar a cidadania no plano da coletividade ou ainda no que tange à determinada classe, seguimento ou grupo da sociedade em face de "preocupações quanto a conflitos entre países” no âmbito geopolítico e ambiental. (PINTO, 2017, p. 19).

Essas Políticas Internacionais promovem a cooperação mútua entre os países de modo a viabilizar a adoção de medidas de cunho protetivo no plano ambiental internacional, uma vez que, determinadas propostas quando aderidas pelos demais Estados soberanos formam uma cadeia global de preservação ao meio ambiente e consequentemente possibilitam a manutenção dos recursos ambientais e processos ecológicos existentes no planeta. (SILVEIRA; GRASSI, 2014, p. 33).

As Políticas Públicas Internacionais podem ser instrumentalizadas em quatro fases, graduações ou formulações basicamente, primeiramente tem-se os planos que promovem as diretrizes fundamentais, os objetivos gerais e as prioridades essenciais a desenvolverem-se em longo prazo, são metas basilares e fundantes que susterão em si todo o peso da demanda social em favor dos requerimentos da comunidade global. (PASCUAL, 2015, p. 29).

Há de se mencionar que os planos acabam por fomentar as diretrizes gerais a serem alcançados e que os mesmos se materializarão por meio dos programas, que são a concretização dos planos elaborados com o enfoque específico em denominado grupo, classe, segmento ou área geográfica, permeados de estratégias educativas e comunicacionais. (HACHE, 2016, p. 36).

Desse modo, os programas internacionais de proteção ambiental propostos pelo Estado soberano necessitam alcançar seus desígnios e propósitos, e é nas ações que os programas se estribam para lograr êxito em atingir a todos seus beneficiários, as ações se constituem em metas estratégicas que alcançam os objetivos estatuídos e que ao serem 
interpostos precisam passar pelo já mencionado plano da efetividade, obtendo sucesso, portanto, em seus propósitos. (SQUIRE, 2015, p. 139).

Por fim, as ações são materializadas pelas atividades que ao consubstanciar todas as práticas e modelos de políticas trazem à existência no plano concreto todos os ideais promovidos pelos planos que embasaram os programas internacionais instrumentalizados pelas ações, que ao serem concretizados pelas atividades propiciam a proteção ambiental, de modo que as atividades trazem à realidade social todas as propostas anteriormente projetadas, sendo materializadas pela mão-de-obra pública ou por entidades privadas, que por seu subsídio viabilizarão todas as práticas e a tão almejada preservação do meio ambiente internacional. (CAFFIO; CARNIMEO; LEANDRO, 2013, p. 170).

Não menos importante, mas igualmente substancial para a proteção ambiental é a existência e imposição de proposições normativas de caráter ambiental internacional, sendo que as referidas se tornam amplos instrumentos protetivos no que tange à preservação do ambiente, de modo a impor deveres e obrigações aos Estados signatários à tratativa e ainda propiciar garantias à manutenção dos processos ecológicos e recursos naturais, onde "as dialéticas entre centro e periferia, ricos e pobres, países desenvolvidos e países subdesenvolvidos" segundo Oliveira (2011b, p. 52-3) são fundamentais, pois de fato os Tratados Internacionais ao serem introduzidos nos ordenamentos pátrios tendem a produzir efeitos de grande valia para a causa ecológica e permitem a consolidação da Geopolítica Ambiental como meio de conservação ambiental, minimizando-se a crise ecológica instaurada na modernidade (OST, 1997, p. 09).

Salienta-se que o período atual reflete inúmeras questões ecológicas internacionais como a temática dos refugiados ou deslocados ambientais que traduz muito bem o objeto da geopolítica ambiental, de modo que a reciprocidade entre Estados e o exercício do poder diplomático governamental tornou-se fundamental para a minimização dos impactos socioambientais e no deslinde, ao menos parcial, de questões que se apresentam cada vez mais recorrentes (CASTRO; RODRÍGUEZ, 2014, p. 285).

Ainda, salienta-se que a principal "característica dos estudos geopolíticos atuais é a opção por uma abordagem plural para a compreensão dos fenômenos relacionados com os conflitos" (FREITAS, 2014, p. 116), de modo que as disputas ambientais atuais ensejam um estudo ainda mais aprofundado das problemáticas, "devendo utilizar-se da diplomacia como instrumento racional" para deslinde de possíveis discussões passiveis de surgimento, como nos declara Garcia e Zacareli (2012, p. 261). 
Essa diplomacia materializa-se nos diversos tratados internacionais de caráter ambiental que estão em vigência na atualidade, a Conferência de Ramsar, sobre zonas úmidas de importância internacional, ocorrida em 1971 no Irã, a Conferência de Estocolmo do ano de 1972, o Relatório Brundtland de 1987, que originou a terminologia desenvolvimento sustentável, a Eco-92 ou Cúpula da Terra realizada no Rio de Janeiro em 1992, o Protocolo de Quioto, efetuado no Japão em 1997, com o intuito de firmar compromissos mais rígidos de redução da emissão dos gases maximizadores do efeito estufa, entre muitos outros, consistindo-se, inquestionavelmente, em fontes materiais de direito ambiental internacional que constituem a materialização da Geopolítica Ambiental. (SCHMIDT; FREITAS, 2012, p. 05).

De fato, a Geopolítica Ambiental é concretizada precipuamente pelos instrumentos normativos internacionais, estabelecendo parâmetros de preservação da biodiversidade e consolidando políticas de proteção dos recursos naturais através de sua metodologia, desenvolvendo mecanismos de gestão internacional dos ecossistemas a partir do caráter de transnacionalidade presente no meio ambiente.

Essa dinâmica de compreensão da relação entre poder e território contribui substancialmente para a causa ambiental ao permitir uma interpretação transnacional e solidária da questão ambiental, e justamente pelo fato de que o meio natural constitui um direito humano é que se estabelecem normativas ambientais globais, garantindo-se os direitos dos cidadãos e viabilizando-se a qualidade de vida das comunidades internacionais.

\section{Considerações finais}

Para concluir, entende-se que os ecossistemas padecem à medida que o homem se desenvolve, o atual modelo de crescimento está ultrapassado, sendo imprescindível a adoção de parâmetros diferenciados de proteção ao meio ambiente de modo a garantir-se uma vida melhor fundada no bem-estar das comunidades internacionais.

A Geopolítica Ambiental representa, desse modo, a materialização dos interesses governamentais e sociais através das políticas internacionais implementadas na conservação do patrimônio ambiental indispensável à sobrevivência estatal e bem-estar da população, permitindo, dessa forma, a preservação dos ecossistemas e manutenção dos processos ecológicos como forma de subsistência da humanidade e sua continuidade, tornando-se ultrapassada aquela visão geográfica e governamental estrita, requerendo-se, portanto, a 
adoção dos mecanismos ora propostos como meio eficiente de solução e deslinde dos desafios emergentes da sociedade moderna industrializada.

Assim, a forma como a geopolítica colabora para a proteção do meio ambiente é evidenciado pelo seu contributo a uma interpretação transnacional da questão ambiental, desenvolvendo meios diplomáticos de discussão da temática ecológica a partir da implantação de uma visão integrada dos ecossistemas no plano global, instituindo instrumentos normativos internacionais como meio de tutela do patrimônio natural.

Desse modo, a exposição apresentada objetivou explanar os principais elementos de concretização de uma geopolítica por intermédio das políticas e normativas internacionais de proteção ao meio natural, evidenciando a forma como esses instrumentos figuram como meio de concretização da Geopolítica Ambiental.

Finalmente, salienta-se que a Geopolítica Ambiental se constitui em uma das grandes representantes atuais dos instrumentos de combate ao dano ambiental, consistindo em um sistema efetivo de promoção à proteção do meio ambiente e que pode tornar-se altamente produtiva na luta pela conservação ambiental no plano internacional.

\section{Referências}

ALBAGLI, Sarita. Geopolítica da biodiversidade. Brasília: IBAMA, 1998.

ALBUQUERQUE, Edu Silvestre de. Uma breve história da geopolítica. Rio de Janeiro: CENEGRI, 2011.

BECKER, Bertha K. Geopolítica da Amazônia. Estudos Avançados, São Paulo, v. 19, n. 53, 2005.

BOSSELMANN, Klaus. O princípio da sustentabilidade. Tradução de Phillip Gil França.

São Paulo: Revista dos Tribunais, 2015.

BROZOSKI, Fernanda Pacheco de Campos. A revalorização geopolítica e geoeconômica

do atlântico sul no sistema internacional. 2013. 115 f. Dissertação (Mestrado em Economia

Política Internacional). Programa de Pós-Graduação em Economia Política Internacional.

Universidade Federal do Rio de Janeiro, Rio de Janeiro, RJ, 2013. 
CAFFIO, Fabio; CARNIMEO, Nicolò; LEANDRO Antonio. Elementi di diritto e geopolitica degli spazi marittimi. Bari, Italia: Caccuci, 2013.

CAMPELLO, Marcelo. A questão ambiental e a nova geopolítica das nações: impactos e pressões sobre a Amazônia brasileira. Espaço Aberto, PPGG - UFRJ, Rio de Janeiro, v. 3, n.2, p. 131-148, 2013a.

CAMPELLO, Marcelo. A questão ambiental e a nova geopolítica das nações: impactos e pressões sobre a Amazônia brasileira. 2013. 138 f. Dissertação (Mestrado em Economia Política Internacional). Programa de Pós-Graduação em Economia Política Internacional. Universidade Federal do Rio de Janeiro, Rio de Janeiro, RJ, 2013b.

CARMONA, Ronaldo Gomes. Geopolítica clássica e geopolítica brasileira contemporânea: Mahan, Mackinder e a "grande estratégia" do Brasil para o século XXI. 2012. 166 f. Dissertação (Mestrado em Geografia Humana). Programa de PósGraduação em Geografia Humana. Universidade de São Paulo, São Paulo, SP, 2012.

CASTRO, William Rodrigo Avendaño; RODRÍGUEZ, Daniel E. Aguilar. Geopolítica y medio ambiente: una mirada a la problemática de los desplazados ambientales. Investigación \& Desarrollo, vol. 22, núm. 2, Jul./Dez., p. 283-308, 2014.

CAUBET, Christian Guy. (Org.) Tratados Internacionais, direitos fundamentais, humanos e difusos: os Estados contra o bem viver das suas populações. Florianópolis Insular, 2013.

COSTA, Wanderley Messias da. Geografia política e geopolítica: discursos sobre o território e o poder. 2 ed. São Paulo: EDUSP, 2008.

DACLON, Corrado Maria. Geopolitica dell'ambiente: sostenibilità, conflitti e cambiamenti globali. Milano: Franco Angeli, 2008.

ESPAÑA. Energía y Geoestrategia. Madrid: Ministerio de Defensa, 2016. 
FONT, Joan Nogué; RUFÍ, Joan Vicente. Geopolítica, identidade e globalização. São Paulo: Annablume, 2006.

FREITAS, Elisa Pinheiro de. A Nova Geopolítica da Energia: Reflexão Sobre os Biocombustíveis. Revista de Geopolítica, v. 5, n. 1, p. 113 - 129, jan./jun. 2014. Disponível em: < http://www.revistageopolitica.com.br/index.php/revistageopolitica/ article/view/ 101/ 100 >. Acesso em: 11 abr. 2018.

GANDRA, Rogério Madruga. Geopolítica antártica no limiar do século XXI: a definição de um projeto estratégico-científico para o Brasil na Antártida. 2013. 200 f. Tese (Doutorado em Geografia). Programa de Pós-Graduação em Geografia. Universidade Federal do Rio Grande do Sul, Porto Alegre, RS, 2013.

GARCIA, Tatiana de Souza Leite; ZACARELI, Murilo Alves. Geopolítica e diplomacia na Bacia Hidrográfica do Nilo. Revista de Geopolítica, v. 3, n. 2, p. 248 - 262, jul./dez. 2012. Disponível em: < http://www.revistageopolitica.com.br/index.php/revista geopolitica/ article/ view/53/62 >. Acesso em: 07 abr. 2018.

GOMES, Róger Walteman. A geopolítica portuária do século XXI no município do Rio Grande/RS: uma proposta de Educação Ambiental Crítica/ Emancipatória. 2013. 108 f. Dissertação (Mestrado em Educação Ambiental). Programa de Pós-Graduação em Educação Ambiental. Universidade Federal de Rio Grande, Rio Grande, RS, 2013.

HACHE, Emmanuel. La géopolitique des énergies renouvelables: amélioration de la sécurité énergétique et/ou nouvelles dépendances? Revue Internationale et Stratégique, LiègeBelgique, n. 101, p. 36-46. 2016. Disponível em: <https://www.cairn.info/revueinternationale-et-strategique-2016-1-page-36.htm>. Acesso em: 11 abr. 2018.

LACOSTE, Yves. La géographie, la géopolitique et le raisonnement géographique. Hérodote, n. 140, p. 19-42, 2008.

LEFF, Enrique. La Geopolítica de la Biodiversidad y el Desarrollo Sustentable: economización del mundo, racionalidad ambiental y reapropiación social de la naturaleza. In: 
Seminário Internacional REG GEN: Alternativas à Globalização. Rio de Janeiro: UNESCO, 2005.

MARTINS, Marcos Antônio Fávaro; PIANOVSKI, Diego. A dimensão geopolítica da questão ambiental. Revista Eletrônica Pro- Docência/UEL, Londrina, n. 5, v. 1, Jul./Dez., 2013.

MURADÁS, Jones. A geopolítica e a formação territorial do sul do Brasil. 2008. 339 f. Tese (Doutorado em Geografia). Programa de Pós-Graduação em Geografia. Universidade Federal do Rio Grande do Sul, Porto Alegre, RS, 2008.

NAVA, Luzma Fabiola; GANDIN, Jérôme. Geopolítica del medio ambiente: cambio climático y recursos hídricos. Aproximación al caso de Canadá. Revista Ábaco, v. 3, n. 85, p. 121-132, 2015. Disponível em: < http://pure.iiasa.ac.at/11916/1/GEOPOL\%C3\%8DTICA \% 20 DEL\%20MEDIOAMBIENTE\%20\%28Gandin\%20\%26\%20Nava\%29.pdf > . Acesso em: 10 abr. 2018.

OLIVEIRA, Leandro Dias de. A geopolítica do desenvolvimento sustentável: um estudo sobre a conferência do Rio de Janeiro (Rio-92). 2011. 298 f. Tese (Doutorado em Geografia). Instituto de Geociências. Universidade Estadual de Campinas, Campinas, SP, 2011a.

OLIVEIRA, Leandro Dias de. A Geopolítica do Desenvolvimento Sustentável na CNUMAD - 1992 (ECO-92): entre o Global e o Local, a Tensão e a Celebração. Revista de Geopolítica, v. 2, n. 1, p. 43 - 56, jan./jun. 2011b. Disponível em: < http://www.revistageopolitica.com.br/ index.php/ revistageopolitica/article/view/21/21 >. Acesso em: 10 abr. 2018.

OLIVEIRA, Lucas Kerr de. Energia como recurso de poder na política internacional: geopolítica, estratégia e o papel do centro de decisão energética. 2012. 400 f. Tese (Doutorado em Ciência Política). Programa de Pós-Graduação em Ciência Política. Universidade Federal do Rio Grande do Sul, Porto Alegre, RS, 2012.

OST, François. A natureza à margem da lei: a ecologia à prova do direito. Lisboa: Instituto Piaget, 1997. 
O'SUlliVAN, Meghan; OVERLAND, Indra; SANDALOW, David. The Geopolitics of Renewable Energy. New York: Columbia University, 2017.

PALTSEV, Sergey. The Complicated Geopolitics of Renewable Energy. Bulletin of the Atomic Scientists, v. 72, n. 6, p. 390-395, 2016. Disponível em: < http://www.tandfonline.com/doi/full/10.1080/00963402.2016.1240476>. Acesso em: 08 abr. 2018.

PASCUAL, Carlos. The New Geopolitics of Energy: the center on global energy policy. Columbia: SIPA, 2015.

PINTO, Elis. Geopolítica da Água. Revista de Geopolítica, v. 8, n. 1, p. 19 - 32, jan./jun. 2017. Disponível em: < http://www.revistageopolitica.com.br/index.php/revista geopolitica/ article/view/172/166 >. Acesso em: 11 abr. 2018.

PFRIMER, Matheus Hoffmann. A Guerra da Água em Cochabamba, Bolívia: desmistificando os conflitos por água à luz da geopolítica. 2009. 409f. Tese (Doutorado em Geografia Humana). Faculdade de Filosofia, Letras e Ciências Humanas. Universidade de São Paulo, São Paulo, 2009.

RAMIARAMTSOA, Hervé Rakoto; BLANC-PAMARD, Chantal; PINTON, Florence. Géopolitique et environnement: les leçons de l'expérience malgache. Marseille: Institut de Recherche pour le Devéloppement, 2012.

RWANYIZIRI, Gaspard. Géopolitique de l'environnement au Rwanda: Pour une gouvernance participative des espaces protégés. 2009. 477f. Tese (Doutorado em Geografia). Institut de Recherche sur les Sociétés et l'Aménagement. Université de Pau et des Pays de l'Adour - UPPA, Pau- France, 2009.

SAAVEDRA, Fernando Estenssoro. La geopolitica ambiental global: el desafio del cambio climático para América Latina. In: WOLFF, Jaime Llambías. (Org.). América Latina: interrogantes y perspectivas. Toronto: York University Press, 2013. 
SANTOS, Waldeir Eustáquio dos. A geopolítica da guerra-fria: a relação entre Turquia e Estados Unidos na estratégia da contenção. 2013. 155 f. Dissertação (Mestrado em Relações Internacionais). Programa de Pós-Graduação em Relações Internacionais. Pontifícia Universidade Católica de Minas Gerais, Belo Horizonte, MG, 2013.

SCHMIDT, Caroline Assunta; FREITAS, Mariana Almeida Passos de. Tratados Internacionais de Direito Ambiental: textos essenciais ratificados pelo Brasil. Curitiba: Juruá, 2012.

SILVA, Golbery do Couto e. Geopolítica do Brasil. Rio de Janeiro: José Olympio, 1967.

SILVEIRA, Clóvis Eduardo Malinverni da. GRASSI, Karine. Configuração e justificação de um direito fundamental ao meio ambiente à luz dos conceitos de meio justo e natureza-projeto em François Ost. Revista Direito e Práxis, Rio de Janeiro, v. 5, p. 76-93, 2014.

SQUIRE, V. Reshaping critical Geopolitics? the materialist challenge. Review of International Studies, v. 41, n. 1, p. 139-159, 2015. Disponível em: <http://wrap.warwick.ac.uk/74091/>. Acesso em: 09 abr. 2018.

SUNDBERG, Juanita. Fronteras íntimas y geopolítica cotidiana en la zona fronteriza entre Estados Unidos-México. Revista de geografía-Norte Grande, Santiago, n. 66, mayo, 2017. Disponível em: < http://www.scielo.cl/pdf/rgeong/n66/art02.pdf >. Acesso em: 10 abr. 2018.

TORRES, Aída Quiñones. Geopolítica de los conflictos socioambientales: resistencia a la expansión minera. Memoria y Sociedad, n. 39, p. 73-92, 2015. Disponível em: <http://dx.doi.org/10.11144/Javeriana.mys19-39.gcsr>. Acesso em: 10 abr. 2018.

ZEINOLABEDIN, Y.; YAHYAPOUR, M.S.; SHIRZAD, Z. Geopolitics and Environmental Issues in the Caspian Sea. Caspian Journal of Environmental Science -CJES. v. 7, n. 2, p. 113-121, 2009. Disponível em: < http://cjes.guilan.ac.ir/pdf_1023_879934ad2b7 d59b38 423 3a544f512c72.html >. Acesso em: 10 abr. 2018. 